\title{
RETROSPECTO LEGISLATIVO E JURISDICIONAL DO FORO POR PRERROGATIVA DE FUNÇÃO NA AÇÃO DE IMPROBIDADE ADMINISTRATIVA
}

\author{
LEGISLATIVE AND JURISDICTIONAL RETROSPECT OF THE JURISDICTION BY \\ POSITION OF FUNCTION IN THE ACTION OF ADMINISTRATIVE IMPROBITY
}

\author{
RETROSPECTO LEGISLATIVOY JURISDICCIONAL DE LA JURISDICCIÓN POR \\ POSICIÓN DE FUNCIÓN EN LA ACCIÓN DE IMPROBIDAD ADMINISTRATIVA
}

\author{
Antonio Miguel Barros Tenório Varjão dos Santos ${ }^{1}$
}

\begin{abstract}
Resumo: Este artigo analisa a Constituição Federa l, a Lei Federal n 8.429 , de 02 de junho de 1992, a Lei Federal $\mathrm{n}^{\circ}$ 10.628, de 24 de dezembro de 2002, o Código de Processo Penal Brasileiro, decisões de vários tribunais e o entendimento de doutrinadores constitucionalistas, penalistas, administrativistas e processualistas com a finalidade de verificar a incidência do foro por prerrogativa de função na ação de improbidade administrativa. Na pesquisa, utiliza-se o método histórico e hipotético-dedutivo, com o lançamento de uma conjectura que será a frontada por uma série de argumentos tendentes a desconstruí-la para a constatação ou não de sua veracidade.
\end{abstract}

Palavras-chave: Improbidade administrativa; Natureza penal; Natureza civil; Foro por prerrogativa de função.

\begin{abstract}
This article analyzes the Federal Constitution, Federal Law No. 8,429, of June 2, 1992, Federal Law No. 10,628, of December 24,2002, the Brazilian Criminal Procedure Code, decisions of various courts and the understanding of constitutionalist, penal, administrative and procedural indoctrinators with the purpose of verifying the incidence of the forum by prerogative of function in the action of administrative improbity. In the research, the historical and hypothetical-deductive method is used, with the launch of a conjecture that will be confronted by a series of arguments tending to deconstruct it for the verification or not of its veracity.
\end{abstract}

Keywords: Administrative improbity; Criminal nature; Civil nature; Forum by prerogative of function.

Resumen: Este artículo ana liza la Constitución Federal, la Ley Federal No. 8.429, del 2 de junio de 1992, la Ley Federal No. 10.628, del 24 de diciembre de 2002, el Código de Procedimiento Penal de Brasil, las decisiones de varios tribunales y la comprensión de estudiosos constitucionalistas, criminalistas, administrativistas y expertos en procedimientos con el fin de evaluar el impacto del foro por función correcta en la acción de mala conducta administrativa. En la investigación, se utiliza el método histórico y hipotético-deductivo, con el lanzamiento de una conjetura que se enfrentará a una serie de argumentos que tienden a deconstruirlo para verificaro no su veracidad.

Palabras clave: Improbabilidad administrativa; Naturaleza criminal; Naturaleza civil; Foro por prerrogativa de función.

\footnotetext{
${ }^{1}$ Bacharel em Direito pela Universidade do Estado da Bahia. Especialista em Direito Constitucional pela Universidade Gama Filho. Mestrando em Administração Pública pela Universidade Federal de Alagoas. Analista Jurídico do Ministério Público de Alagoas. E-mail: antoniomiguel.tvs@gmail.com
} 


\section{Introdução}

A Constituição da República Federativa do Brasil, de 5 de outubro de 1988, em seu art. $37, \S 4^{\circ}$, prevê, no ápice do sistema jurídico nacional, que a improbidade administrativa será punida com a perda da função pública e com a suspensão dos direitos políticos, independentemente da sanção penal cabível.

Apesar de não conceituá-la, a Constituição Federal deixa claro, através das sanções que comina, que o ato de improbidade administrativa é gravíssimo, e que seu autor deve ser afastado dos negócios do Estado, não sendo conveniente sequer que ele participe da escolha dos representantes do povo através do voto.

Em 2 de junho de 1992, promulgou-se a Lei Federal $n^{\circ} 8.429$, que, em sede inf raconstitucional, regulou o citado art. $37, \S 4^{\circ}$, da Carta de Outubro, apresentando os sujeitos ativos e passivos da improbidade administrativa, os atos puníveis, seus elementos subjetivos, as penalidades aplicáveis e os aspectos processuais da ação que requer o reconhecimento do ato ímprobo e a punição do agente. Entretanto, nem a Constituição Federal nem a Lei Geral de Improbidade Administrativa declararam expressamente qual o foro competente para a apreciação das ações de improbidade administrativa.

Em 24 de dezembro de 2002, promulgou-se a Lei Federal $n^{\circ} 10.628$, que modificou o Código de Processo Penal, entre outras coisas, acrescentando um $\S 2^{\circ}$ ao art. 84 para determinar que, nos casos de foro por prerrogativa de função, o mesmo tribunal competente para a apreciação da ação penal o seria também para as ações de improbidade administrativa.

A Lei Federal $n^{\circ} 10.628 / 2002$, contudo, foi declarada inconstitucional pelo Supremo Tribunal Federal, em sede de controle concentrado de constitucionalidade, na ação direta de inconstitucionalidade $\mathrm{n}^{\circ}$ 2797-2, produzindo efeitos erga omnes e vinculando os demais órgãos do Poder Judiciário e do Poder Executivo.

Ocorre que, eventualmente, o Supremo Tribunal Federal e o Superior Tribunal de Justiça têm se declarado competentes para a apreciação de ações de improbidade administrativa propostas contra ocupantes de elevados cargos públicos, como ministros de Tribunais Superiores e governadores de Estado.

Ao lado disso, tratando do foro por prerrogativa de função nas ações penais, entre as quais, segundo o Supremo Tribunal Federal e parcela amplamente majoritária da doutrina, não se incluem as ações de improbidade administrativa, a Suprema Corte declarou a existência de uma mutação constitucional que alterou a prerrogativa de foro de algumas autoridades, que, segundo esse novo entendimento, só tem foro por prerrogativa de função nas ações relativas a supostas irregularidades praticadas no curso do mandato atual e quando as supostas irregularidades têm relação com o cargo ocupado. Esta decisão do Supremo, embora não trate especificamente do tema central deste artigo, apresenta subsídios para a compreensão da resistência do Poder Judiciário em reconhecer a prerrogativa de foro nas ações de improbidade administrativa. 
Em sede legislativa, tramita noCongresso Nacional a Proposta de Emenda à Constituição $n^{\circ} 358 / 2005$, que, caso aprovada, terá o mesmo conteúdo, mas hierarquia distinta, da Lei Federal $\mathrm{n}^{\circ} 10.628 / 2002$, que previa o foro por prerrogativa de função para as ações de improbidade administrativa. É neste contexto que se indaga, como pergunta de pesquisa, se existe foro por prerrogativa de função nas ações de improbidade administrativa.

O objetivo deste artigo é, portanto, investigar a incidência da prerrogativa de função nas ações de improbidade e, para tanto, se analisará a natureza das ações de improbidade administrativa, bem como as iniciativas legislativas e as decisões judiciais relacionadas com a fixação da competência para processamento e julgamento de ações de improbidade administrativa.

Na confecção deste trabalho utiliza-se o método de pesquisa histórico e o hipotéticodedutivo, que se caracteriza pela exposição de uma conjectura inicial a uma série de argumentos contrários a fim de verificar se aquela se sustenta.

A conjectura, no caso, é a de que, embora a Constituição Federal tenha fixado expressamente $\mathrm{o}$ foro por prerrogativa de função para as ações penais e que ele possa ser inferido para as ações penaliformes, como a ação de improbidade administrativa, mesmo quando expressamente previsto em lei, ele, o foro por prerrogativa de função, enfrenta a resistência do Poder Judiciário por conta de a opinião pública associá-lo, nem sempre de acertadamente, à morosidade e à impunidade. Trata-se de uma postura de populismo judicial.

\section{Improbidade administrativa e ação civil pública}

A Constituição Federal de 1988 e a Lei Federal no 8.429/92 nada dizem a respeito do foro competente para a apreciação da ação de improbidade administrativa. Parcela amplamente majoritária da doutrina e da jurisprudência nacional costuma aplicar subsidiariamente a Lei Federal $n^{\circ} 7.347$, de 24 de julho de 1985, que disciplina a ação civil pública, à ação de improbidade administrativa, sem, porém, explicitar as razões de fazê-lo. Em sentido contrário, negando a aplicação subsidiária do rito da ação civil pública à ação de improbidade administrativa, registra-se a posição de Arnoldo Wald e Rodrigo Garcia da Fonseca (2006).

$\mathrm{O}$ art. $1^{\circ}$ da Lei da Ação Civil Pública enumera os bens cuja reparação do dano material ou moral pode ser promovida através da ação por ela regulada, sendo eles: o meio-ambiente; os direitos do consumidor; os bens e direitos de valor artístico, estético, histórico, turístico e paisagístico; qualquer outro interesse difuso ou coletivo; a ordem econômica, e; a ordem urbanística.

Com efeito, a fórmula geral utilizada no inciso IV do art. $1^{\circ}$ da Lei Federal $\mathrm{n}^{\circ} 7.347 / 85$, "qualquer outro interesse difuso ou coletivo", conduziria ao entendimento de que as normas reguladoras da açãocivil pública deveriam ser aplicadas subsidiariamente à ação por improbidade administrativa se a finalidade desta fosse a exclusivamente a reparação do dano. 
As sanções da improbidade administrativa, contudo, são mais amplas, abarcando, além da reparação do dano, a perda da função pública, a suspensão dos direitos políticos, a pro ibição de contratar com os poderes públicos e a multa civil.

Desprezando a gravidade destas penas, parcela amplamente majoritária da jurisprudência e da doutrina, a exemplo de Emerson Garcia e Rogério Pacheco Alves (2006), Marino Pazzaglini Filho (2009), Waldo Fazzio Júnior (2007) e Silvio Antonio Marques (2010), aplica à ação por improbidade administrativa o art. $2^{\circ}$ da Lei da Ação Civil Pública que determina que as ações por ela reguladas serão propostas no foro do local onde ocorrer o dano e seu respectiv o juízo terá competência para processar e julgar a causa.

O professor Marcelo Figueiredo (2004), inclusive, apesar de não mencionar expressamente a ação regulada pela Lei Federal no 7.347/85, apresenta a ação de improbidade administrativa com objetivos semelhantes ao da ação civil pública, dizendo que a "natureza essencial das sanções previstas na lei é civil, e não penal. Verifica-se que todo o esforço do legislador está no sentido de ressarcir e recompor os danos causados pela conduta do administrador ímprobo" (p. 178).

O órgão judiciário competente para a apreciação e o julgamento da ação por improbidade administrativa seria, segundo essa linha de intelecção, é o Juízo de Direito da comarca onde ocorreu o dano. Caso hajainteresse da União, o órgão competente parao julgamento da ação seria o Juízo Federal da Seção ou Subseção Judiciária onde ocorreu o dano.

Este entendimento foi reforçado pelo julgamento da Ação Direta de Inconstitucionalidade $\mathrm{n}^{\circ}$ 2797-2, que declarou que a ação tendente a concretizar as sanções da improbidade administrativa tem natureza civil. A decisão não foi unânime, merecendo registro as divergências vencidas apresentadas pelo Ministro Gilmar Ferreira Mendes, que vislumbrou nas graves sanções políticas - a perda da função pública e a suspensão dos direitos políticos - a essência da improbidade administrativa.

\section{Improbidade administrativa e ação penal}

Conforme anteriormente exposto, a prática do ato de improbidade administrativa enseja sanções cuja gravidade impele sua classificação entre os institutos do Direito Penal. Recorde-se que a nascente normativa do instituto da improbidade administrativa no ordenamento jurídico brasileiro, o art. 37, $\S 4^{\circ}$, da Constituição da República, dispõe que a improbidade administrativa será punida com a perda da função pública e com a suspensão dos direitos políticos.

Ocorre que, como o mesmo dispositivo constitucional afirma que as penalidades acima referidas serão aplicadas sem prejuízo da ação penal cabível, uma enorme parcela da doutrina e da jurisprudência sustenta, com base quase que exclusivamente na fórmula "sem prejuízo da ação penal cabível" e sem uma análise profunda focada no próprio instituto da improbidade administrativa, que a sua natureza jurídica é civil ou não penal. 
Entre os que sustentam a natureza jurídica civil ou não penal da improbidade administrativa baseados na expressão "sem prejuízo da ação penal cabível”, tem-se a respeitável doutrina de Alexandre de Morais e de Fábio Konder Comparato. Este afirma quese "Constituição distingue e separa a ação condenatória do responsável por atos de improbidade administrativa às sanções por ela expressas, da ação penal cabível, é, obviamente, porque aquela demanda não tem natureza penal" (COMPARATO, 1999, p. 6). Aquele afirma que

A natureza civil dos atos de improbidade administrativa decorre da redação constitucional, que é bastante clara ao consagrar a independência da responsabilidade civil por ato de improbidade administrativa e a possível responsabilidade penal, derivadas da mesma conduta, ao utilizar a fórmula ".... sem prejuízo da ação penalcabível".

Em sentido contrário, uma parcela diminuta da doutrina buscou identificar a natureza jurídica do instituto da improbidade administrativa olhando para a gravidade as suas sanções, até porque o dispositivo originário da improbidade administrativa no ordenamento jurídico brasileiro, o multicitado art. $37, \S 4^{\circ}$, da Constituição Federal, aponta para o fato de que elas, as sanções, integram a essência do instituto da improbidade.

Nesta linha de intelecção, Vanderlei Anibal Junior e Sergio Roxo da Fonseca (2007, p. 1) sustentam que:

\begin{abstract}
A ação de improbidade administrativa tem a natureza jurídica de uma ação penal, pois no seu bojo aplica-se penas ao acusado, subtraindo-lhe os atributos da cidadania e da vida honrada, ou seja, são-lhe aplicadas penas conceituadas como as mais graves do sistema jurídico em vigor. É o condenado posto "ad metallum" com a suspensão de direitos políticos e proibição de celebrar contratos com órgãos públicos, numa saudosa recordação das penas medievais do direito filipino.
\end{abstract}

Alguns autores, como André Pimentel Filho (2011, p. 25), apesar de percebem a natureza essencialmente penal do instituto da improbidade administrativa, preferem, talvez pela larga predominância da doutrina majoritária, negar, com base na fórmula "sem prejuízo da ação penal cabível", a natureza penal da improbidade:

Nada obstante as dúvidas que em princípio a proximidade ontológica com a esfera penal possam suscitar, eis que aqui ta mbém estamos no campo do direito sancionador, atualmente é fora de questão sua natureza civil (rectius, nãopenal). $\mathrm{O}$ próprio legislador constituinte deixou isto claro e quis assim ao registrar que as punições aplicáveis ao praticante do ato de improbidade são "sem prejuízo da ação penalcabível".

O desvelar da natureza jurídica do instituto da improbidade administrativa não é um capricho de preciosismo doutrinário, masuma necessidade prática, tendo em vistaos reflexos que isto pode produzir na vida das pessoas e na rotina da Administração Pública.

Se a improbidade administrativa for, diante da gravidade de suas sanções, um instituto ontologicamente penal, apesar da fórmula "sem prejuízo da sanção penal cabível”, que 
regramento processual deveria lhe ser aplicável? Se, onde há a mesma razão deve haver o mesmo direito, então, as graves sanções da improbidade administrativa devem ser antecedidas pelas amplas garantias do processo penal que antecedem as graves sanções do direito penal.

\section{Improbidade administrativa e foro por prerrogativa de função}

A Constituição Federal, de 5 de outubrode 1988, desloca dos juízes de primeiro grau para os tribunais de justiça, os tribunais regionais federais, o Superior Tribunal de Justiça e o Supremo Tribunal Federal a competência originária para o julgamento de algumas autoridades.

Por força do inciso I do art. 102 da Constituição da República, compete ao Supremo TribunalFederal processar e julgar originariamente: (i) nas inf rações penais comuns, o Presidente da República, o Vice-Presidente, os membros do Congresso Nacional, seus próprios Ministros e o Procurador-Geral da República, e; (ii) nas infrações penais comuns e nos crimes de responsabilidade, os Ministros de Estado e os Comandantes da Marinha, do Exército e da Aeronáutica, os membros dos Tribunais Superiores, os do Tribunal de Contas daUniãoe os chefes de missão diplomática de caráter permanente.

Ao Superior Tribunal de Justiça, por seu turno, por força do inciso I do art. 105 da Constituição da República, compete processar e julgar originariamente, nos crimes comuns, os Governadores dos Estados e do Distrito Federal, e, nestes e nos de responsabilidade, os desembargadores dos Tribunais de Justiça dos Estados e do Distrito Federal, os membros dos Tribunais de Contas dos Estados e do Distrito Federal, os dos Tribunais Regionais Federais, dos Tribunais Regionais Eleitorais e do Trabalho, os membros dos Conselhos ou Tribunais de Contas dos Municípios e os do Ministério Público da União que oficiem perante tribunais.

O art. 108 da Carta de Outubro atribui aos Tribunais Regionais Federais a competência originária para o julgamento dos juízes federais da área de sua jurisdição, incluídos os da Justiça Militar e da Justiça do Trabalho nos crimes comuns e de responsabilidade, e os membros do Ministério Público da União, ressalvada a competência da Justiça Eleitoral e o inciso III do art. 96 atribui privativamente aos Tribunais de Justiça a competência para julgar os juízes estaduais e do Distrito Federal e Territórios, bem como os membros do MinistérioPúblico nos crimes comuns e de responsabilidade, também ressalvada a competência da Justiça Eleitoral.

Ademais, o inciso X do art. 29 da Constituição Federal determina que as leis orgânicas dos municípios prevejam o julgamento do prefeito pelo Tribunal de Justiça1 e o Superior Tribunal de Justiça, em inúmeros julgados como o conflito de competência $\mathrm{n}^{\circ} 105.227 / \mathrm{TO}$, tem reconhecido o direito, derivado do art. $27, \S 1^{\circ}$, de os deputados estaduais serem processados e julgados originariamente pelos Tribunais de Justiça.

Tal direito de julgamento por um órgão jurisdicional superior não pode ser confundido com uma regalia pessoal, mas como um requisito que possibilita o exercício da função pública. Neste sentido lecionam Guilherme de Souza Nucci (2007), Julio Fabbrini Mirabete (1997), 
Fernando Capez (1997), Fernando Tourinho Filho (1990), Nestor Távora e Rosmar Rodrigues Alencar (2010).

Em sede jurisprudencial, a quinta turma do Superior Tribunal de Justiça ofereceu no julgamento do Habeas Corpus 99773/RJ, relatado pelo Ministro Napoleão Nunes Maia Filho, uma breve explicação dos motivos para a existência do foro por prerrogativa de função:

O foro especial por prerrogativa funcional não é privilégio pessoal do seu detentor, mas garantia necessária ao pleno exercício de funções públicas, típicas do Estado Democrático de Direito: é técnica de proteção da pessoa que o detém, em face de dispositivo da Carta Magna, significando que o titular se submete a investigação, processo e julgamento por órgão judicial previamente designado, não se confundindo, de forma alguma, com a idéia de impunidade do agente.

Entendendo que o julgamento das ações por improbidade administrativa pode sofrer as mesmas influências e causar o mesmo embaraço que as ações penais, o Congresso Nacional e o Presidente da República editaram a Lei Federal n 10.628, de 24 de dezembro de 2002, modificando a redação do caput do art. 84 do Código de Processo Penal e acrescentando-lhe dois parágrafos.

Com a mudança, o $\S 2^{\circ}$ do art. 84 do Código de Processo Penal determinava que, no caso de foro por prerrogativa de função, a ação de improbidade administrativa fosse processada e julgada pelo mesmo órgão competente para a apreciação da ação penal.

Essa inovação legislativa sofreu duras críticas da doutrina. Entre os críticos, Marino Pazzaglini Filho (2009), Waldo Fazzio Júnior (2007), Silvio Antonio Marques (2010), Emerson Garcia e Rogério Pacheco Alves (2006).

Em sentido contrário, mesmo antes da expressa previsão legislativa, Arnoldo Wald e Gilmar Ferreira Mendes (1998) sustentavam o foro por prerrogativa de função para a ação de improbidade administrativa, sob o fundamento de que a mesma razão que autoriza o foro privilegiado para a ação penal impõe sua aplicação na ação de improbidade administrativa, haja vista a gravidade das consequências desta advinda, e que esta solução está implícita no texto constitucional.

Numa posição intermediária, o professor Hugo Nigro Mazzilli (2003) defendia que apenas as ações de improbidade administrativa com pedido de perda da função pública e suspensão dos direitos políticos fossem julgadas pelos órgãos competentes para o julgamento do crime de responsabilidade.

A Associação Nacional dos Membros do Ministério Público levou a questão ao conhecimento do Supremo Tribunal Federal, através da ação direta de inconstitucionalidade $\mathrm{n}^{\circ}$ 2797, oportunidade em que se declarou a Lei Federal $n^{\circ}$ 10.628/2002 formalmente inconstitucional sob o argumento de que a lei ordinária não teria o condão de ampliar a competência original dos tribunais, o que só poderia ser feito mediante Emenda à Constituição. 
Atualmente, tramita no Congresso Nacional a Proposta de Emenda à Constituição no 358/2005 com vistas a inserir na Constituição Federal um dispositivo com a seguinte redação: "A ação de improbidade de que trata o art. $37, \S 4^{\circ}$, referente a crime de responsabilidade dos agentes políticos, será proposta, se for o caso, perante o tribunal competente para processar e julgar criminalmente o funcionário ou autoridade na hipótese de prerrogativa de função".

Essa tentativa estender o foro de prerrogativa de função para as ações de improbidade administrativa também tem recebido críticas da doutrina que revelam outros motivos que subjazem à declaração de inconstitucionalidade formal da Lei Federal $n^{\circ}$ 10.628/2002 pelo Supremo Tribunal Federal.

O Presidente da Associação dos Juízes Federais do Brasil, Walter Nunes da Silva Júnior (2007), criticando a Proposta de Emenda à Constituição $n^{\circ}$ 358/2005, sustenta que os tribunais tem dificuldades operacionais para instruir os processos, o que gera morosidade e sensação de impunidade. Entre as mazelas do foro por prerrogativa de função, o citado Juiz Federal af irma que não há registro na história de que qualquer tribunal brasileiro tenha alguma vez condenando algum político.

Com efeito, a aparência de privilegio e a impunidade que o corporativismo muitas vezes proporciona, fazem do foro privilegiado uma solução com pouca aceitação social - o que, de alguma maneira, se reflete na doutrina e na jurisprudência - mesmo nos casos expressamente autorizados pela Constituição. Por vício na aplicação, o foro privilegiado tem sido identificado como imunidade para a prática de condutas socialmente nocivas por ocupantes de elevados cargos públicos.

Ocorre que, independentemente desse sentimento, a Constituição Federal reconhece o foro de prerrogativa de função comoum importante instrumento de viabilidade dafunção pública, que, sem ele, estaria ex posto ao tumulto das pressões políticas que mais facilmente inclinam um juiz de primeiro grau.

Apesar da decisão proferida em sede de controle concentrado de constitucionalidade, talvez até em virtude do corporativismo, o Supremo Tribunal Federal tem modificado seu posicionamento a respeito do tema.

A petição 3211/DF, tendo como parte o Ministro Gilmar Ferreira Mendes, suscitou uma questão de ordem perante o Supremo Tribunal Federal sobre a sua competência para apreciar ações de improbidade administrativa ajuizadas contra seus ministros, e nessa ocasião se decidiu que o tribunal seria competente, conforme ementa adiante transcrita:

Questão de ordem. Ação civil pública. Ato de improbidade administrativa. Ministro do Supremo Tribunal Federal. Impossibilidade. Competência da Corte para processar e julgar seus membros apenas nas infrações penais comuns.

1. Compete ao Supremo Tribunal Federal julgar ação de improbidade contra seus membros.

2. Arquivamento da ação quanto a o Ministro da Suprema Corte e remessa dos 
autos ao Juízo de $1^{\circ}$ grau de jurisdição no tocante a os demais.

Depois desse precedente, o Superior Tribunal de Justiça também modificou seu entendimento e decidiu, entre outros, o agravo Regimental no Recurso especial no 1.216 .168 RS, de relatoria do Ministro Humberto Martins, reconhecendo-se competente para o julgamento da governadora do Rio Grande do Sul Yeda Crusius por ato de improbidade administrativa.

No acórdão do citado agravo regimental consta um trecho do voto do Ministro Teori Zavascki que merece ser novamente transcrito:

Bem se vê, portanto, que, mesmo em relação às regras sobre competências jurisdicionais, os dispositivos da Constituição comportam interpretação ampliativa, para preencher vazios e abarcar certas competências implícitas, mas inegáveis, por força do sistema. Sob o ponto de vista constitucional, justifica-se, a ssim, com sobradas razões, a preservação de prerrogativa de foro também para a ação de improbidade administrativa, entendimento que, a lém de fundado em boa doutrina (v.g.: WALD, Arnoldo; MENDES, Gilmar Ferreira. Competência para julgar ação de improbidade administrativa. Re vista de Informação Legislativa, v. 35, n. 138, p. 215; TOJAL, Sebastião Botto de Barros; CAETANO, Flávio Crocce. Competência e prerrogativa de foro em ação civil de improbidade administrativa. In: BUENO, Cássio Scarpinella; PORTO FILHO, Pedro Paulo de Rezende (coord.). Improbidade administrativa : questões polêmicas e atuais, p. 399), recebeu o aval do STF, no precedente citado (QO na Pet. 3.211-0, rel. P/ acórdão Min. Menezes Direito, DJ 27.06.2008)e do STJ, na Reclamação 2115, antes referida.

No caso de Governador de Estado, a Constituição lhes assegura, nos crimes comuns, o foro por prerrogativa de função perante o STJ (art. 105, I, a) e, nos de responsabilidade, perante a respectiva Assembléia Legislativa (Lei $1.079 / 50$, art. 77 e 78). Não se compadece com esse regime o reconhecimento da competência de juiz de primeiro grau para processar e julgar ação civil pública por improbidade administrativa, que pode acarretar a perda de cargo para o qual foi eleito por sufrágio popular, fonte primária de legitima ção do poder $\left(\mathrm{CF}\right.$, art. $1^{\circ}$, pará grafo único). É de se reconhecer que, por inafastável simetria com o que ocorre em relação a os crimes comuns, há, em casos tais, competência implícita complementar do Superior Tribunal de Justiça.

Diante da semelhança da gravidade das sanções, o acusado numa ação de improbidade administrativa merece as mesmas garantias do acusado num processo penal - entre elas, o foro por prerrogativa de função.

\section{Antipatia popular contra o foro por prerrogativa de função}

A Constituição Federal, ao fixar a competência do Supremo Tribunal Federal, dispôs, no art. 102, inciso I, alínea $b$, que a instituição deveria julgar, originariamente, nas infrações penais comuns, o Presidente da República, o Vice-Presidente, os membros do Congresso Nacional, seus próprios Ministros e o Procurador-Geral da República.

Nota-se que o tex to constitucional não faz nenhuma ressalva e, por exemplo, não diz que o Supremo Tribunal Federal só é competente para julgar as referidas autoridades quando o crime em questão tem relação com o cargo exercido ou quando o crime em questão tenha sido cometido durante o tempo que a pessoa sob julgamento exercia o cargo público. 
Ocorre que, no julgamento de questão de ordem na ação penal n. 937, o Supremo Tribunal Federal, modificou o seu entendimento anterior para restringir - com base nas sensações coletivas de morosidade, impunidade e de desigualdade, que trazem indignação sociale desprestígio contra Suprema Corte - o alcance da prerrogativa de foro.

A leitura da ata de julgamento da referida questão de ordem revela uma grande preocupação dos ministros do STF com o prestígio da Corte, talvez uma preocupação maior do que a preocupação de extrair do Texto Constitucional o seu exato conteúdo.

No julgamento em questão, o ministro Barroso, que atuou como relator, afirmou que "aqui no Supremo, segundo dados da Assessoria de Gestão Estratégica, já prescreveram, desde que o Supremo passou a atuar nesta matéria, mais de 200 processos. Portanto, essa é uma estatística que traz constrangimento e desprestígio para o Supremo Tribunal Federal", "acho que há um problema da não vocação; há um problema do desprestígio, porque a gente não consegue desempenhar bem este papel; e há uma questão jurídica", "o sistema é ruim; o sistema funciona mau; o sistema traz desprestígio para o Supremo; o sistema traz impunidade", "os resultados negativos são muito óbvios para nós desmentirmos, que são a impunidade e o desprestígio que isso traz para o Supremo", "tudo o quefazcom que a Justiça funcione mal, tudo o que desprestigie o que a gente simboliza e faz deve ser revisitado. Logo, se está funcionando mal, nós temos que fazer alguma coisa, dentro dos limites que a Constituição permita”.

Ocorre que, no anseio de resolver situações que o Supremo Tribunal Federal entende problemáticas, as soluções adotadas frequentemente não estão dentro dos limites que a Constituição permite, ou seja, sob a justificativa de fazer o que supostamente entender ser justo, o Supremo Tribunal Federal não se constrange em desprezar o que está escrito na Constituição.

O Supremo Tribunal Federal agiu assim, desprezando o que está escrito na Constituição Federal para atender a um suposto clamor social, neste caso, quando restringiu o foro por prerrogativa de função, quando passou a admitir o cumprimento da pena de prisão antes do trânsito em julgado, e quando negou, para outras autoridades, com exceção de seus próprios ministros, o foro por prerrogativa de função nas ações de improbidade administrativa.

\section{Conclusão}

Apesar de majoritário entendimento doutrinário e jurisprudencial, a gravidade das sanções da improbidade administrativa recomenda sua classificação entre os institutos do direito penal.

Nesta esteira, não convêm a aplicação analógica do regulamento da ação civil pública à ação de improbidade administrativa, visto que aquela pretende precipuamente a reparação do dano, enquanto esta pretende a punição do agente ímprobo, afastando-o temporariamente dos negócios estatais. Não é adequado, portanto, aplicar a ação de improbidade administrativa institutos como, por exemplo, a revelia, cabível na ação civil pública. 
Enquanto é aceitável condenar alguém à reparação de um dano que eventualmente não causou apenas porque não se defendeu na ação civil pública, não o é condenar alguém a perda da função pública (eventualmente eletiva) e a suspensão dos direitos políticos pelo mesmo motivo o não comparecimento ao processo. Por outro lado, os motivos que autorizam o foro por prerrogativa de função na açãopenal também o autorizam na ação de improbidade administrativa.

Com efeito, assim como é inconveniente que um juiz de primeiro grau embarace o exercício de um mandado conferido pelo povo através do julgamento de uma ação penal, é inconveniente a perda da função pública e a suspensão dos direitos políticos de um alto dignitário do Estado por um magistrado de primeiro grau numa ação de improbidade administrativa.

Como visto, o foro por prerrogativa de função não é um privilégio pessoal nem um salvoconduto para a prática de delitos para ocupantes de elevados cargos públicos, masum instrumento necessário à atividade política, que de alguma forma a blinda de ataques jurídicos com finalidades meramente eleitorais. Também por isso, não há que se falar em quebra da isonomia.

A resistência da doutrina e da jurisprudência em vislumbrar a aplicação do foro por prerrogativa de função à ação de improbidade administrativa, ao que parece, é também fruto de um sentimento de impunidade decorrente da morosidade e da omissão de muitos tribunais no julgamento de ações penais contempladas em sua competência originária.

Inconveniente, portanto, não é o foro por prerrogativa de função, mas a postura morosa e omissa de alguns tribunais, bem como o reconhecimento da prerrogativa apenas para algumas autoridades, como Ministros do Supremo Tribunal Federal, autorizando-se uma interpretação sistemática da Constituição Federal em alguns casos e negando-a em outros, sem que entre eles haja qualquer distinção.

Sobre essas discrepâncias da interpretação Constitucional, convêm mencionar os ensinamentos de Lenio Luiz Streck (2014, p. 1) sobre a Teoria da Katchanga:

\begin{abstract}
Discutiendo sobre el papeldel "des-aniversario", para el que existían 364 días de recepción de regalos en general, y sólo uno de cumpleaños, Humpty Dumpty dice a Alicia: "la gloria es para ti". Ella responde: "No sé qué quieres decir con la gloria", a lo que él con desdén, replica, "Seguro que no lo sabes... hasta que yo te diga. Quiero decir 'es un bello y devastador argumento para usted'" Pero, dice Alicia, "la gloria no significa 'un argumento hermoso y devastador". Y Humpty Dumpty concluye: "Cuando yo uso una palabra, significa exactamente lo que yo quiero que signifique, ni más ni menos". Tengamos en cuenta esa última frase del personaje nominalista de Lewis Caroll... La palabra "gloria" significa lo que él quiere que signifique... Es el "demoledor" corolario a todo posible argumento. Como así también lo es la Katchanga (Real).
\end{abstract}

O Supremo Tribunal Federal não pode, sem infringir as leis da lógica e do bom senso, e sem se valer de "katchanga" (Streck, 2014, p.1), dizer que a ação de improbidade administrativa tem natureza civil; que, por isso, nela não cabe o foro por prerrogativa de função; mas se declarar competente para o julgamento quando o réu é um de seus Ministros. 
Assim como os Ministros do Supremo Tribunal Federal, todas as autoridades cuja competência para o julgamento das ações penais a Constituição Federal retira do juiz de primeiro grau para atribuir a um órgão colegiado composto por magistrados mais experientes, pelas mesmas razões, tem direito ao foro por prerrogativa de função nas ações de improbidade administrativa.

\section{Referências}

ANIBAL JUNIOR, Vanderlei; FONSECA, Sergio Roxo da. Natureza penal da sanção por improbidade administrativa. Migalhas. São Paulo, 17 de janeiro de 2007. Disponível em: $<$ www.migalhas.com.br/depeso/34430/natureza-penal-da-sancao-por-improbidadeadministrativa>. Acesso em: 24 jul. 2020.

CAPEZ, Fernando. Curso de processo penal. São Paulo: Saraiva, 1997.

COMPARATO, Fábio Konder. Ação de improbidade: lei no 8.429/92: competência ao juízo de $1^{\circ}$ grau. Boletim dos Procuradores da República. São Paulo, n. 9, p. 6-9, jan. 1999.

FAZZIO JÚNIOR, Waldo. Atos de improbidade administrativa. São Paulo: Atlas, 2007.

FIGUEIREDO, Marcelo. Probidade administrativa. 5. ed. São Paulo: Malheiros, 2004.

GARCIA, Emerson; ALVES, Rogério Pacheco. Improbidade administrativa. 3. ed. Rio de Janeiro: Lumen Juris, 2006.

MARQUES, Silvio Antonio. Improbidade administrativa. São Paulo: Saraiva, 2010.

MAZZILLI, Hugo Nigro. O Foro por Prerrogativa de Função e a Lei n. 10.628/02. Revista Síntese de Direito Penal e Processual Penal. Porto Alegre, v. 3, n. 18, p. 33-37, fev./mar. 2003.

MENDES, Gilmar Ferreira; WALD, Arnoldo. Competência para julgar ação de improbidade administrativa. Revista de Informação Legislativa. Brasília v. 35 n. 138, abr./jun., p.123-135, 1998

MIRABETE, Julio Fabbrini. Processo penal. 7 ed. São Paulo: Saraiva, 1997.

NUCCI, Guilherme de Souza. Manual de processo penal e execução penal. 3. ed. São Paulo: Revista dos Tribunais, 2007.

PAZZAGLINI FILHO, Marino. Lei de improbidade administrativa comentada. 4. ed. São Paulo: Atlas, 2009.

PIMENTEL FILHO, André. Desafios na aplicação da lei de improbidade. Revista da Procuradoria Geral do Estado do Espírito Santo. Vitória, v. 11, n. 11, p. 15-55, 2011.

SILVA JUNIOR, Walter Nunes. Privilegiar para quê? Correio Brasiliense. Brasília, 31 mai 2007.

STRECK, Lenio Luiz. Decisionismo, ponderación y Katchanga real. Revista Europea de Historia de las Ideas Políticas y de las Instituciones Públicas, v. 4, n. 8, p. 114-131, 2014.

TÁVORA, Nestor; ALENCAR, Rosmar Rodrigues. Curso de direito processual penal. 4. ed. Salvador: Jus Podivm, 2010.

TOURINHO FILHO, Fernando. Processo penal. 12. ed. São Paulo: Saraiva, 1990. vol. 2.

WALD, Arnoldo; FONSECA, Rodrigo Garcia da. Ação de improbidade administrativa. Revista de Direito da Câmara Municipal do Rio de Janeiro. Rio de Janeiro, v. 6, n. 2, p. 73-79, 2006. 